\title{
Fetal cardiovascular alterations in twin-to-twin transfusion syndrome
}

\author{
Ioana Cristina Rotar ${ }^{1,2}$, Gabriela Zaharie ${ }^{3,4}$, Adelina Staicu ${ }^{1}$, \\ Andreia Preda ${ }^{1}$, Daniel Mureșan ${ }^{1,2}$
}

1) $1^{\text {st }}$ Department of Obstetrics and Gynecology, Iuliu Hatieganu University of Medicine and Pharmacy, Cluj-Napoca, Romania

2) $1^{\text {st }}$ Clinic of Obstetrics and Gynecology, Emergency County Hospital, Cluj-Napoca, Romania

3) Neonatal Department, Iuliu Hatieganu University of Medicine and Pharmacy, Cluj-Napoca, Romania

4) Neonatal Department, Emergency County Hospital, Cluj-Napoca, Romania

DOI: $10.15386 / \mathrm{mpr}-1481$

Manuscript received: 06.10 .2019

Received in revised form: 15.12.2019

Accepted: 30.12.2019

Address for correspondence:

drandreia@yahoo.com

This work is licensed under a Creative Commons Attribution-NonCommercialNoDerivatives 4.0 International License

\section{Introduction}

Monochorionic

diamniotic

(MCDA) twin pregnancies occur in approximately $70-75 \%$ of monozygotic twinning and have an increased risk of adverse perinatal outcomes $[1,2]$. The specific challenges of monochorionic pregnancies arise from the particular vascularization of a shared placenta [3]. Assisted reproductive techniques, by using day 5 blastocyst transfers, sociodemographic changes and delaying of pregnancy to a later maternal age, increases the prevalence of both dichorionic and monochorionic twinning $[4,5]$.

\begin{abstract}
Twin-to-twin transfusion syndrome (TTTS) is the consequence of vascular
anastomoses of the shared placenta of monochorionic twin pregnancies. Both
circulating inter-twin blood flow and vasoactive mediators imbalance cause
hypovolemia in the donor and hypervolemia in the recipient fetus. If left untreated,
TTTS has a high perinatal mortality rate and adverse long-term outcomes mainly
Abstract
Twin-to-twin transfusion syndrome (TTTS) is the consequence of vascular
anastomoses of the shared placenta of monochorionic twin pregnancies. Both
circulating inter-twin blood flow and vasoactive mediators imbalance cause
hypovolemia in the donor and hypervolemia in the recipient fetus. If left untreated,
TTTS has a high perinatal mortality rate and adverse long-term outcomes mainly

Abstract
Twin-to-twin transfusion syndrome (TTTS) is the consequence of vascular
anastomoses of the shared placenta of monochorionic twin pregnancies. Both
circulating inter-twin blood flow and vasoactive mediators imbalance cause
hypovolemia in the donor and hypervolemia in the recipient fetus. If left untreated,
TTTS has a high perinatal mortality rate and adverse long-term outcomes mainly cardiovascular and neurological.

The recipient has cardiovascular changes including atrioventricular valve regurgitation, diastolic dysfunction and pulmonary stenosis/atresia. The maladaptive response to vascular changes determines a constant decreased blood flow in the donor that permanently modifies the arterial structure leading to postnatal alterations in the vascular system. Fetoscopic LASER surgery of placental vascular anastomoses may disrupt the underlying pathophysiology and improves cardiovascular function with normalization of systolic and diastolic function within weeks after treatment.

The impact of cardiovascular changes is relevant for the safety of the management of a TTTS case. The improvement of the perinatal survival after intrauterine surgery leads to viable infants with the longer-term sequelae. Therefore accurate quantification of cardiovascular involvement is essential for clinicians for pregnancy management but also for patient counseling about the potential treatment options the outcome.
\end{abstract}

Keywords: twin-to-twin transfusion syndrome, vascular anastomosis, monochorionic diamniotic twin pregnancies, recipient fetus, donor fetus 


\section{The placental circulation in MCDA} pregnancies

The placental vascular anastomoses allow a direct vascular connection between the twins. The arterioarterial (AA) and veno-venous (VV) anastomoses are direct, superficial end-to-end anastomoses located on the chorionic plate. The blood flow through these anastomoses is bidirectional [9]. The unidirectional arterio-venous (AV) anastomoses are located at the capillary level, where a cotyledon is supplied by an artery of one twin (the donor) and blood is drained through a vein into the circulation of the other twin (the recipient) [10].

In MCDA pregnancies, placental characteristics determine the occurrence of severe complications, including selective intrauterine growth restriction (sIUGR), twin-twin transfusion syndrome (TTTS) and spontaneous twin anemia-polycythemia sequence (TAPS) [3]. The three forms are not totally separate entities, the overlap being possible.

The association between specific combinations of anastomoses and the development of complications in MCDA twins has been studied [11]. While AV anastomoses are found in all TTTS placentas, fact demonstrated by both fetoscopic and pathologic studies (postnatal injections) [12], AA anastomoses are rarer in TTTS placentas compared with uncomplicated MCDA pregnancies $[13,14]$. This fact leads to the conclusion that AA anastomoses may play an important role in preventing the development of TTTS. AA protective role was studied both in vitro and in vivo $[15,16]$. Conflicting data exist about $\mathrm{VV}$ anastomoses, some studies suggesting that this type of anastomoses may increase the risk of TTTS [17], while others reported a comparable or lower prevalence of VV anastomoses in TTTS placentas compared to nonTTTS placentas [9].

The type, number, size and location of vascular anastomoses may vary between the different subgroups of MC twin placentas. The analysis of the differences regarding the angioarchitecture helps elucidate the specific role of the various anastomoses in the development of specific complications in MC pregnancies [16]. TTTS develops when unbalanced deep artery-to-vein anastomoses allow a net transfer of fluid from one twin to its co-twin in the absence of a compensatory AA or contralateral AV anastomoses [18].

Beside the blood shift from donor to recipient, in TTTS the twins are also exposed to the endocrine environment and vasoactive mediators produced by each other [11]. In response to hypovolemia, the compensatory mechanisms increase the secretion of vasoactive mediators in the donor, which may in turn be transferred to the recipient [19]. Therefore, the cardiovascular system of the recipient twin is affected at several sites: preload, cardiac function and afterload [13].

\section{TTTS pathophysiology}

TTTS is a severe condition, usually present between 15 and 25 weeks of gestation; its precise initiating mechanisms remain uncertain [20]. The condition is essentially hemodynamic, the continuing volume shift resulting in hypervolemia in the recipient and hypovolemia in the donor, with activation of additional hormonal factors [21]. Vasoactive mediators, especially endothelin I (ET-1) is implicated in systemic hypertension of recipient [22]. Moreover ET-1 levels directly correlate with the severity of the recipient hydrops [22]. Natriuretic peptides, localized predominantly to the distal convoluted tubules of the fetal kidney, heart and brain, are responsible in the recipient for the increased glomerular filtration rate and decreased tubular reabsorption, leading to an increased urinary output and polyhydramnios [23,24]. Hypovolemia and chronic hypoperfusion of the donor kidneys determine oliguria and oligohydramnios.

Discordant renin-angiotensin-aldosterone system (RAAS) activation seems also to play a role in TTTS pathogenesis. Elevated cord blood renin levels have been observed in both twins, although renin mRNA and protein are upregulated in donor and down-regulated in recipient kidneys [25]. Angiotensin II (AT-2) increases peripheral vascular resistance and causes secretion of aldosterone from the adrenal cortex, which increases tubular reabsorption of sodium and fluid to regulate against hypovolemia. Although AT-2 activity seems to maintain the donor's blood pressure higher levels could potentially decrease renal and placental blood flow worsening donor oliguria and oligohydramnios [26]. Both twins are exposed to high levels of RAS components and placental anastomoses could play a role of in the transfer of RAAS components from donor to recipient [27]. The blood flow shift to the recipient fetus and prolonged exposure of the donor twin to vasoconstrictive influence aggravate renal hypoperfusion, resulting in persistent activation of RAAS thus maintaining the vicious circle [28].

\section{Recipient cardiovascular pathophysiology}

Monochorionic twins are known to have an increased risk for congenital heart defects even in the absence of TTTS with only one twin mainly affected [29]. The cardiovascular impact of TTTS is due to altered hemodynamics with volume-overload and increased peripheral vascular resistance from vasoactive mediators [30]. These could cause systolic and diastolic dysfunction in both twins. Functional cardiovascular changes appear in the early stages and may lead to structural heart disease. In approximately $70 \%$ of the cases the recipient twin shows echocardiographic signs of cardiovascular complications at the time of diagnosis [31].

Ultrasound Doppler examinations of the arterial, venous and cardiac systems are used for the assessment 
of the fetal circulation. Unbalanced blood volume in TTTS with preload changes in the venous compartment makes umbilical venous flow to be significantly higher in recipients than in donors [32]. In advanced disease severity, umbilical venous flow decreases in recipients as a sign of cardiac system inability to accommodate venous return. Impaired cardiac function leads to abnormal flow patterns in ductus venosus [33].

The ductus venosus (DV) is a vascular shunt that acts as a pressure transducer and reflects pressure-volume changes in the fetal heart [34]. DV Doppler assessment is used to monitor the response to fetoscopic LASER surgery and in the early stratification of patients who are at risk of developing TTTS [35]. At the time of diagnosis, blood flow abnormalities occur significantly more often in the recipient than in the donor and have been correlated with development of hydrops and with lower survival in the recipient twin. Abnormal blood flow in the DV in advanced stages is characterized by increased pulsatility and subsequently absent or reversed flow during atrial contraction [36].

The relative prolongation of systolic flow and shortening of diastolic filling time indicates impaired ventricular filling in the recipient heart [37]. The diastolic dysfunction usually precedes and is more pronounced than the systolic dysfunction [38]. Evaluation of the myocardial performance index (MPI) could bring further understanding of the cardiac adaptation in TTTS fetuses [39]. This parameter evaluates both systolic and diastolic myocardial function representing the quotient of the sum of the duration of isovolumetric contraction time (ICT) and isovolumetric relaxation time (IRT) divided by the ejection time (ET). Prolonged ICT, IRT and higher MPI are found in recipients at all TTTS stages due to a slow chronic increase in volume load with increased ventricular dimensions [40]. An important atrioventricular valve regurgitation is present and often extending throughout more than half of the cardiac cycle $[41,42]$. The consequent changes in ventricular shape and morphology appear due to the local wall stress resulting in local fibrosis and cell death. In addition, pressure overload, the result of the release of vasoactive factors in the donor twin (such as angiotensin II and endothelin I, which are also transferred to the recipient twin through vascular anastomoses) determines hypertrophic cardiomyopathy and right ventricular outflow tract abnormalities in the recipient [43]. Major changes in preload and afterload could lead to decreased ventricular strain of both ventricles in recipient in the early stages of TTTS [40].

Abnormal Doppler evaluation of blood flow in the umbilical artery is a less common finding in the recipient and is probably a consequence of placental compression from polyhydramnios or heart failure with severely reduced systolic function [41].

True pulmonary stenosis/atresia is not a characteristic of MCDA twins, being present even in the absence of TTTS [35]. Secondary to right heart dysfunction, with right heart enlargement, cardiomegaly and tricuspid valve regurgitation, the flow through the pulmonary valve decreases potentially leading to narrowing and stenosis (figures 1,2). The resultant functional pulmonary valve stenosis resolves completely following LASER therapy in $80-90 \%$ of the cases $[44,45]$.

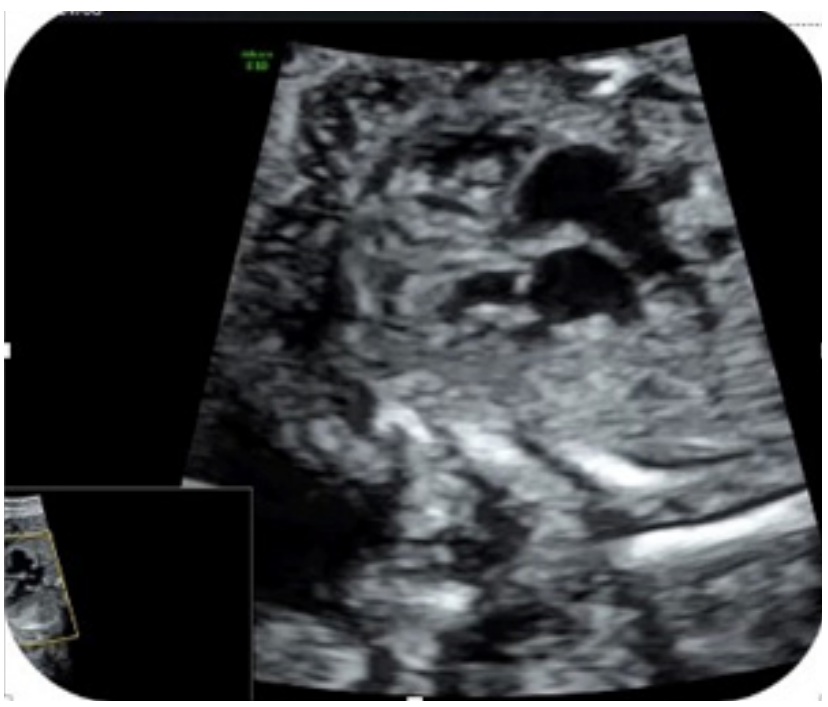

Figure 1. B mode great vessels evaluation: pulmonary stenosis, hyperechoic pulmonary valves and poststenotic dilatation.

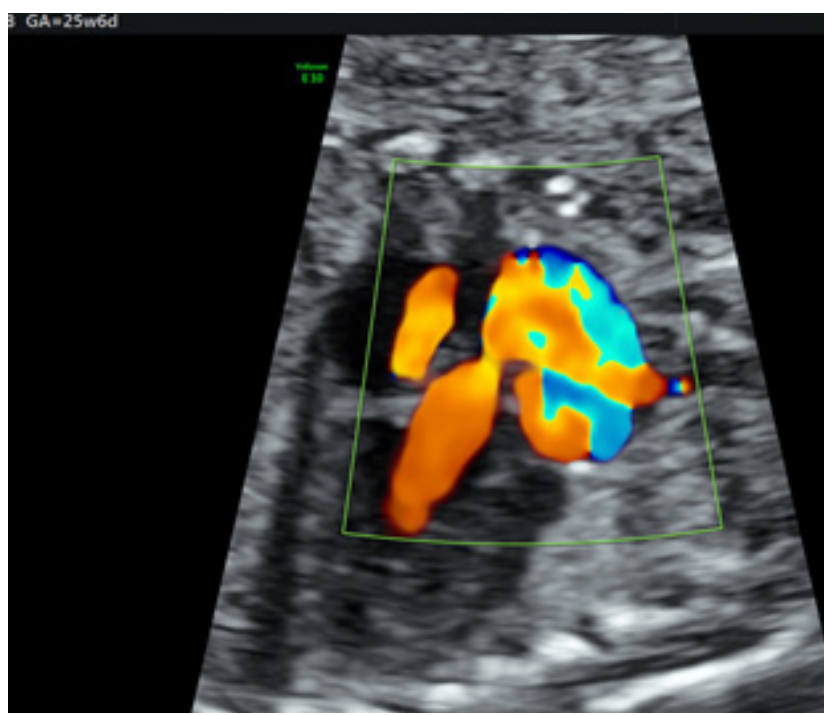

Figure 2. CFM evaluation. Stenotic pulmonary valve and poststenotic dilatation.

\section{Donor cardiovascular pathophysiology}

Although donor fetuses usually have normal echocardiographic parameters at diagnosis of TTTS, they are already hypovolemic and having a lowered renal perfusion. The maladaptive humoral response to pressure changes induces a constant decreased blood flow in the 
donor which modifies permanently the arterial structure leading to postnatal alterations in the vascular system [46]. Increased collagen synthesis, smooth muscle hypertrophy and vascular medial hypertrophy are permanent physical changes in the systemic arteries responsible for vascular stiffness of surviving donors in childhood [31].

Ductus venosus abnormalities are less prevalent in the donor than in the recipient twin. Hypovolemia determines DV inlet dilatation favoring an increased blood flow through the DV. In only about $3-10 \%$ of the cases abnormal Doppler waveforms or increased transmission of the pulse wave into the UV are present [10].

The increased umbilical artery pulsatility indices in the donor twins suggest increased placental resistance. These may be due to a primary maldevelopment of the placenta and unequal placental sharing combined with hemodynamic imbalance and hypovolemia [47]. Absence or reversal of end-diastolic velocities in the umbilical artery represent risk factors for intrauterine fetal demise of donor twin after selective LASER photocoagulation of communicating vessels [48].

\section{Cardiovascular long-term implications}

Even though the TTTS is known to be associated with high rates of mortality, and the survival of both fetuses is rare, a high percentage of morbidity is reported for the surviving fetuses.

Earlier reports suggested an abnormal cardiovascular outcome in up to $38-46 \%$ of the recipient twins, mainly signs of right heart disease, in utero or postnatal [46]. Myocardial hypertrophy, significant tricuspid regurgitation, atrial septal defect, pulmonary valve stenosis requiring postnatal balloon valvuloplasty were common before the use of selective fetoscopic LASER photocoagulation (SFLP) as the therapy of choice [30].

Early-onset advanced TTTS and potential adverse effects from co-twin demise are associated with a high perinatal loss rate and risk of severe neurologic impairment among survivors [49]. If SFLP is performed several weeks before delivery, the changes in hemodynamics allows cardiac remodeling and resolution of tricuspid regurgitation [50]. Probably the plasticity of the fetal tissues permits the cardiac remodeling after the removal of the stressor factor [51].

Multiple studies indicate that congenital heart disease is over-represented in MCDA twins compared with the general population, been encountered even in TTTS. A possible explanation is a shared genetic etiology but further studies are needed [52]. Heart disease causes approximately half of the postnatal deaths of the recipient twins. Even after the fetoscopic LASER surgery, they bear a long-term risk for cardiac disease compared to the general population [53]. Altered fetal blood flow in TTTS could lead to an increased risk of coarctation of the aorta or a hypoplastic aortic arch in the donor twin and right ventricular outflow tract anomalies (RVOT) and atrial septal defect in the recipient [52,54].

Ventricular hypertrophy with tricuspid regurgitation in the recipient may conduct to valve dysplasia, stenosis, regurgitation, or functional atresia for the recipient. RVOT anomalies in $\mathrm{MC}$ pregnancies occur not only in recipients but also in donors, after a transient hydrops [55]. Immediate and long term impact on the tricuspid valve is unknown and in some cases they may require longer-term follow-up and even postnatal treatment [56].

In conclusion, cardiac acquired lesions determined probably by both altered hemodynamics and vasoactive mediators can progress despite the functional improvement perhaps due to a structural damage. Increased experience with LASER techniques together with improved early neonatal care and survival, can ameliorate TTTS prognosis, but there is still a risk of developing postnatal cardiovascular sequelae [57].

\section{Antenatal therapy and its implication on the cardiovascular system}

Fetoscopic LASER photocoagulation of placental vascular anastomoses is nowadays the first line treatment in patients with TTTS $[53,58]$. There are many LASER coagulation protocols. Recent data suggest that the use of Solomon technique, the coagulation of the vascular equator of the chorionic surface is superior to selective coagulation of anastomoses regarding TAPS or TTTS recurrence, but no difference has been found between the two technique for long term morbidity and mortality [59]. Therapeutic options utilized in the past ranged from expectant therapy, to invasive procedures such as repeated amniocentesis, selective reduction and amniotic septostomy. All these methods lead to an improvement in overall perinatal survival compared with untreated TTTS [31]. The classification used for TTTS stadialization described by Quintero is depicted in table I.

Table I. The Quitero classification of TTTS [60].

\begin{tabular}{l|c|c|c|c|c} 
Stage & Poly/oligohydramnios sequence & Absent bladder in the donor & Abnormal Doppler & Hydrops & Demise \\
\hline I & + & - & - & - \\
II & + & + & - & - \\
III & + & + & + & - & - \\
IV & + & + & + & - & + \\
V & + & + & + & + & +
\end{tabular}

*Abnormal Doppler: absent end diastolic flow, reverse end diastolic flow, pulsatile umbilical venous flow 
The results of multicentric randomized trials proved the superiority of LASER treatment over serial amnioreductions in terms of survival and neurologic morbidity for Quintero stage $\geq 2$ TTTS [28]. The occlusion of the vascular connections between the twins stops the abnormal blood circulation, improving the cardiovascular function in the recipient with normalization of systolic and diastolic function [30,47].

The perinatal outcome following the fetoscopic procedures improved over the years being related to the evolution of the LASER technique, operator learning curve, amelioration of the referral timing and improved early neonatal care [61]. The treated fetuses need to be followed up carefully by periodic ultrasound assessment of the fetal heart, brain, limbs, serial Doppler velocities [58].

The impact of LASER therapy on fetal cardiac function and hemodynamic variables in TTTS was extensively investigated [47]. Significant improvement of systolic function and cardiac contractility of both ventricles was observed in recipients after interrupting the transfer of fluids and mediators [62]. SFLP alters both preload and afterload, with a significant decrease in DV pulsatility index and normalization of time intervals with lengthening of filling times. As a consequence, improved diastolic heart function was present in the recipient twin [33]. Therefore after the correction of the hemodynamic imbalance the majority of fetuses will recover without developing RVOT anomalies [63]. Although 9 up to $12.5 \%$ had persistent anomalies requiring postnatal treatment [63].

In the donor, rapid increase in left ventricular filling pressure, volume and cardiac output result in reappearance of end-diastolic flow in the UA and a significant increase of pulsatility index after the procedure [40]. Umbilical venous flow is increased by more than $50 \%$ in donor within 48 hours of SFLP and improved renal perfusion is reflected by reappearance of bladder filling [64]. The volume-overload in the donor is occasionally accompanied by transient hydrops [62]. In case of hydrops, up to one third of fetuses develop RVOT anomalies directly following LASER therapy [56]. Fortunately, the majority of hydropic infants with TTTS have normal cardiac outcomes following intrauterine LASER surgery [55].

Despite improved survival, a number of fetuses are at high risk for intrauterine demise after LASER coagulation. One of the strongest predictors of recipient demise is preoperative echocardiographic evidence of TTTS cardiomyopathy [65]. The losses of fetal recipients treated by SFLP usually occur within 24 hours of the procedure [66]. Postoperative signs of cardiac overload in both twins and the presence of congenital heart diseases are associated with significant morbidity and mortality $[65,67]$.

\section{Conclusions}

TTTS is associated with an increased risk of perinatal morbidity and mortality. Quintero staging system is currently used for the assessment of TTTS severity.
Currently, fetoscopic LASER surgery has become the primary treatment, with the intention to increase the chance of survival of at least one twin. In severe untreated cases, the mortality rate is as high as $90 \%$ and even with treatment, there is an increased risk of neurological and cardiac complications, as well as a significant risk of preterm birth.

The impact of cardiovascular changes in terms of cerebral perfusion and longer-term neurological development is relevant on the safest course of management and possible outcomes. Considering that perinatal survival for TTTS is improved, understanding the longer-term sequelae is highly important. Accurate assessment and quantification of cardiovascular involvement is essential for pregnancy management. It is also important to emphasize the long-term cardiac sequelae of the surviving fetuses while counseling the parents on the current treatment possibilities.

\section{References}

1. NICE. Twin and triplet pregnancy [NG137]. 2019. Available from: www.nice.org.uk/guidance/ng137

2. Kilby M, Baker P. Multiple Pregnancy. Kilby M, Baker P CH and FD, editor. London: RCOG Press at the Royal College of Obstetricians and Gynaecologists; 2006.

3. Kilby MD, Bricker L on behalf of the Royal College of Obstetricians and Gynaecologists. Management of Monochorionic Twin Pregnancy: Green-top Guideline No. 51. BJOG. 2017;124:e1-e45.

4. Nakasuji T, Saito H, Araki R, Nakaza A, Nakashima A, Kuwahara A, et al. The incidence of monozygotic twinning in assisted reproductive technology: analysis based on results from the 2010 Japanese ART national registry. J Assist Reprod Genet. 2014;31:803-807.

5. Kawachiya S, Bodri D, Shimada N, Kato K, Takehara Y, Kato O. Blastocyst culture is associated with an elevated incidence of monozygotic twinning after single embryo transfer. Fertil Steril. 2011;95:2140-2142.

6. Denbow ML, Cox P, Taylor M, Hammal DM, Fisk NM. Placental angioarchitecture in monochorionic twin pregnancies: relationship to fetal growth, fetofetal transfusion syndrome, and pregnancy outcome. Am J Obstet Gynecol. 2000; 182:417-426.

7. Fischbein R, Nicholas L, Aultman J, Baughman K, Falletta L. Twin-twin transfusion syndrome screening and diagnosis in the United States: A triangulation design of patient experiences. PLoS One. 2018;13:e0200087.

8. Umur A, van Gemert MJ, Nikkels PG. Monoamniotic-versus diamniotic-monochorionic twin placentas: anastomoses and twin-twin transfusion syndrome. Am J Obstet Gynecol. 2003;189:1325-1329.

9. Hack KE, Nikkels PG, Koopman-Esseboom C, Derks JB, Elias SG, van Gemert MJ, et al. Placental characteristics of monochorionic diamniotic twin pregnancies in relation to perinatal outcome. Placenta. 2008;29:976-981.

10. Wohlmuth C, Gardiner HM, Diehl W, Hecher K. Fetal cardiovascular hemodynamics in twin-twin transfusion 
syndrome. Acta Obstet Gynecol Scand. 2016;95:664-671.

11. Lewi L, Deprest J, Hecher K. The vascular anastomoses in monochorionic twin pregnancies and their clinical consequences. Am J Obstet Gynecol. 2013;208:19-30.

12. Diehl W, Hecher K, Zikulnig L, Vetter M, Hackelöer BJ. Placental vascular anastomoses visualized during fetoscopic laser surgery in severe mid-trimester twin-twin transfusion syndrome. Placenta. 2001;22:876-881.

13. Lopriore E, Slaghekke F, Middeldorp JM, Klumper FJ, van Lith JM, Walther FJ, et al. Accurate and simple evaluation of vascular anastomoses in monochorionic placenta using colored dye. J Vis Exp. 2011;55:e3208.

14. de Villiers SF, Slaghekke F, Middeldorp JM, Walther FJ, Oepkes D, Lopriore E. Arterio-arterial vascular anastomoses in monochorionic placentas with and without twin-twin transfusion syndrome. Placenta. 2012;33:652-654.

15. De Paepe ME, Shapiro S, Greco D, Luks VL, Abellar RG, Luks $\mathrm{CH}$, et al. Placental markers of twin-to-twin transfusion syndrome in diamniotic-monochorionic twins: A morphometric analysis of deep artery-to-vein anastomoses. Placenta. 2010;31:269-276.

16. Zhao DP, de Villiers SF, Slaghekke F, Walther FJ, Middeldorp JM, Oepkes D, et al. Prevalence, size, number and localization of vascular anastomoses in monochorionic placentas. Placenta. 2013;34:589-593.

17. Zhao DP, Cohen D, Middeldorp JM, Klumper FJ, Haak MC, Oepkes D, et al. The role of veno-venous anastomoses in twintwin transfusion syndrome. Placenta. 2014;35:334-336.

18. Lewi L, Cannie M, Blickstein I, Jani J, Huber A, Hecher K, et al. Placental sharing, birthweight discordance, and vascular anastomoses in monochorionic diamniotic twin placentas. Am J Obstet Gynecol. 2007;197:587.e1-e8.

19. Quintero RA. Twin-twin transfusion syndrome. Clin Perinatol. 2003;30:591-600.

20. Lewi L, Jani J, Blickstein I, Huber A, Gucciardo L, Van Mieghem T, et al. The outcome of monochorionic diamniotic twin gestations in the era of invasive fetal therapy: a prospective cohort study. Am J Obstet Gynecol. 2008;199:514.e1-e8.

21. Moon-Grady AJ. Fetal echocardiography in twin-twin transfusion syndrome. Am J Perinatol. 2014;31 Suppl $1: \mathrm{S} 31-\mathrm{S} 38$.

22. Bajoria R, Sullivan M, Fisk NM. Endothelin concentrations in monochorionic twins with severe twin-twin transfusion syndrome. Hum Reprod. 1999;14:1614-1618.

23. Bajoria R, Ward S, Chatterjee R. Natriuretic peptides in the pathogenesis of cardiac dysfunction in the recipient fetus of twin-twin transfusion syndrome. Am J Obstet Gynecol. 2002; 186:121-127.

24. Bajoria R, Ward S, Sooranna SR. Atrial natriuretic peptide mediated polyuria: pathogenesis of polyhydramnios in the recipient twin of twin-twin transfusion syndrome. Placenta. 2001;22:716-724.

25. Fisk NM, Duncombe GJ, Sullivan MH. The basic and clinical science of twin-twin transfusion syndrome. Placenta. 2009;30:379-390.

26. Mahieu-Caputo D, Meulemans A, Martinovic J, Gubler MC, Delezoide AL, Muller F, et al. Paradoxic activation of the renin-angiotensin system in twin-twin transfusion syndrome: an explanation for cardiovascular disturbances in the recipient
Pediatr Res. 2005;58:685-688.

27. Galea P, Barigye O, Wee L, Jain V, Sullivan M, Fisk NM. The placenta contributes to activation of the renin angiotensin system in twin-twin transfusion syndrome. Placenta. 2008;29:734-742.

28. Djaafri F, Stirnemann J, Mediouni I, Colmant C, Ville Y. Twin-twin transfusion syndrome - What we have learned from clinical trials. Semin Fetal Neonatal Med. 2017;22:367-375.

29. Manning N, Archer N. Cardiac Manifestations of Twinto-Twin Transfusion Syndrome. Twin Res Hum Genet. 2016;19:246-254.

30. Habli M, Michelfelder E, Livingston J, Harmon J, Lim FY, Polzin W, et al. Acute effects of selective fetoscopic LASER photocoagulation on recipient cardiac function in twin-twin transfusion syndrome. Am J Obstet Gynecol 2008;199:412.e1-6.

31. Karatza AA, Wolfenden JL, Taylor MJ, Wee L, Fisk NM, Gardiner HM. Influence of twin-twin transfusion syndrome on fetal cardiovascular structure and function: prospective casecontrol study of 136 monochorionic twin pregnancies. Heart. 2002;88:271-277.

32. Rossi AC, D'Addario V. The efficacy of Quintero staging system to assess severity of twin-twin transfusion syndrome treated with laser therapy: a systematic review with metaanalysis. Am J Perinatol. 2009;26:537-544.

33. Tachibana D, Glosemeyer P, Diehl W, Nakagawa K, Wada $\mathrm{N}$, Kurihara Y, et al. Time-interval analysis of ductus venosus flow velocity waveforms in twin-to-twin transfusion syndrome treated with laser surgery. Ultrasound Obstet Gynecol. 2015;45:544-550.

34. Braga M, Moleiro ML, Guedes-Martins L. Clinical Significance of Ductus Venosus Waveform as Generated by Pressure - volume Changes in the Fetal Heart. Curr Cardiol Rev. 2019;15:167-176.

35. Seravalli V, Miller JL, Block-Abraham D, Baschat AA. Ductus venosus Doppler in the assessment of fetal cardiovascular health: an updated practical approach. Acta Obstet Gynecol Scand. 2016;95:635-644.

36. Bensouda B, Fouron JC, Raboisson MJ, Lamoureux J, Lachance C, Leduc L. Relevance of measuring diastolic time intervals in the ductus venosus during the early stages of twin-twin transfusion syndrome. Ultrasound Obstet Gynecol. 2007;30:983-987.

37. Stirnemann JJ, Mougeot M, Proulx F, Nasr B, Essaoui M, Fouron JC, et al. Profiling fetal cardiac function in twintwin transfusion syndrome. Ultrasound Obstet Gynecol. 2010;35:19-27.

38. Moon-Grady AJ, Rand L, Gallardo S, Gosnell K, Lee H, Feldstein VA. Diastolic Cardiac Pathology and Clinical TwinTwin Transfusion Syndrome in Monochorionic/Diamniotic Twins. Am J Obstet Gynecol. 2011;205:279.e1-e279.e11.

39. Lobmaier SM, Cruz-Lemini M, Valenzuela-Alcaraz B, Ortiz JU, Martinez JM, Gratacos E, et al. Influence of equipment and settings on myocardial performance index repeatability and definition of settings to achieve optimal reproducibility. Ultrasound Obstet Gynecol. 2014;43:632-639.

40. Ortiz JU, Torres X, Eixarch E, Bennasar M, Cruz-Lemini M, Gómez O, et al. Differential Changes in Myocardial Performance Index and Its Time Intervals in Donors and 
Recipients of Twin-to-Twin Transfusion Syndrome before and after laser Therapy. Fetal Diagn Ther. 2018;44:305-310.

41. Rychik J, Tian Z, Bebbington M, Xu F, McCann M, Mann $\mathrm{S}$, et al. The twin-twin transfusion syndrome: spectrum of cardiovascular abnormality and development of a cardiovascular score to assess severity of disease. Am J Obstet Gynecol. 2007;197:392.e1-e8.

42. Van Mieghem T, Eixarch E, Gucciardo L, Done E, Gonzales I, Van Schoubroeck D, et al. Outcome prediction in monochorionic diamniotic twin pregnancies with moderately discordant amniotic fluid. Ultrasound Obstet Gynecol. 2011;37:15-21.

43. Ortiz JU, Masoller N, Gómez O, Bennasar M, Eixarch E, Lobmaier SM, et al. Rate and Outcomes of Pulmonary Stenosis and Functional Pulmonary Atresia in Recipient Twins with Twin-Twin Transfusion Syndrome. Fetal Diagn Ther. 2017;41:191-196.

44. Rychik J, Tian Z, Bebbington M, Moldenhauer J, Khalek N, Johnson M. Evaluation of the cardiovascular system in twintwin transfusion syndrome: it's not about 'scores' but about 'goals'. Ultrasound Obstet Gynecol. 2010;36:647-648.

45. Barrea C, Hornberger LK, Alkazaleh F, McCrindle BW, Roberts A, Berezovska O, et al. Impact of selective laser ablation of placental anastomoses on the cardiovascular pathology of the recipient twin in severe twin-twin transfusion syndrome. Am J Obstet Gynecol. 2006;195:1388-1395.

46. Chescheir NC. Twin-to-twin transfusion syndrome: a model for the fetal origins of adult health. Paediatr Perinat Epidemiol. 2005;19 Suppl 1:32-36.

47. Van Mieghem T, Klaritsch P, Doné E, Gucciardo L, Lewi P, Verhaeghe $\mathrm{J}$, et al. Assessment of fetal cardiac function before and after therapy for twin-to-twin transfusion syndrome. Am J Obstet Gynecol. 2009;200:400.e1-e7.

48. Kontopoulos EV, Quintero RA, Chmait RH, Bornick PW, Russell Z, Allen MH. Percent absent end-diastolic velocity in the umbilical artery waveform as a predictor of intrauterine fetal demise of the donor twin after selective laser photocoagulation of communicating vessels in twin-twin transfusion syndrome. Ultrasound Obstet Gynecol. 2007;30:35-39.

49. Lenclen R, Ciarlo G, Paupe A, Bussieres L, Ville Y. Neurodevelopmental outcome at 2 years in children born preterm treated by amnioreduction or fetoscopic laser surgery for twin-to-twin transfusion syndrome: comparison with dichorionic twins. Am J Obstet Gynecol. 2009;201:291.e1-e5.

50. Khalek N, Johnson MP, Bebbington MW. Fetoscopic laser therapy for twin-to-twin transfusion syndrome. Semin Pediatr Surg. 2013;22:18-23.

51. Herberg U, Gross W, Bartmann P, Banek CS, Hecher K, Breuer J. Long term cardiac follow up of severe twin to twin transfusion syndrome after intrauterine laser coagulation. Heart. 2006;92:95-100.

52. Wagner S, Repke JT, Ural SH. Overview and Long-term Outcomes of Patients Born With Twin-to-Twin Transfusion Syndrome Rev Obstet Gynecol. 2013;6:149-154.

53. Barrea C, Debauche C, Williams O, Jasienski S, Steenhaut P, Sluysmans T, et al. Twin-to-twin transfusion syndrome: perinatal outcome and recipient heart disease according to treatment strategy. J Paediatr Child Health. 2013;49:E28-E34.
54. van den Boom J, Battin M, Hornung T. Twin-twin transfusion syndrome, coarctation of the aorta and hypoplastic aortic arch: a case series report. J Paediatr Child Health. 2010;46:76-79.

55. Gray PH, Ward C, Chan FY. Cardiac outcomes of hydrops as a result of twin-twin transfusion syndrome treated with laser surgery. J Paediatr Child Health 2009;45:48-52.

56. Eschbach SJ, Boons LSTM, Van Zwet E, Middeldorp JM, Klumper FJCM, Lopriore E, et al. Right ventricular outflow tract obstruction in complicated monochorionic twin pregnancy. Ultrasound Obstet Gynecol. 2017;49:737-743.

57. Gijtenbeek M, Shirzada MR, Ten Harkel ADJ, Oepkes D, C Haak M. Congenital Heart Defects in Monochorionic Twins: A Systematic Review and Meta-Analysis. J Clin Med. 2019;8. doi: 10.3390/jcm8060902.

58. Senat MV, Deprest J, Boulvain M, Paupe A, Winer N, Ville Y. Endoscopic laser surgery versus serial amnioreduction for severe twin-to-twin transfusion syndrome. N Engl J Med. 2004;351:136-144.

59. Lecointre L, Sananès N, Weingertner AS, Gaudineau A, Akladios C, Cavillon V, et al. Fetoscopic laser coagulation in 200 consecutive monochorionic pregnancies with twintwin transfusion syndrome. J Gynecol Obstet Hum Reprod 2017;46:175-181.

60. Quintero RA, Morales WJ, Allen MH, Bornick PW, Johnson PK, Kruger M. Staging of twin-twin transfusion syndrome. J Perinatol. 1999;19(8 Pt 1):550-555.

61. Akkermans J, Peeters SH, Klumper FJ, Lopriore E, Middeldorp JM, Oepkes D. Twenty-Five Years of Fetoscopic Laser Coagulation in Twin-Twin Transfusion Syndrome: A Systematic Review. Fetal Diagn Ther. 2015;38:241-253.

62. Wohlmuth C, Boudreaux D, Moise KJ Jr, Johnson A, Papanna $\mathrm{R}$, Bebbington $\mathrm{M}$, et al. Cardiac pathophysiology in twintwin transfusion syndrome: new insights into its evolution. Ultrasound Obstet Gynecol. 2018;51:341-348.

63. Khalek N, VillaA, Johnson M, Moldenhaur J, Martinez-Poyer J, Rychick J. 144: Echocardiography follow up performed at two years in monochorionic pairs affected by twin twin transfusion syndrome who underwent selective LASER photocoagulation. Am J Obstet Gynecol. 2014;210(Suppl):S86.

64. Baschat AA, Gungor S, Glosemeyer P, Huber A, Hecher K. Changes in umbilical venous volume flow after fetoscopic laser occlusion of placental vascular anastomoses in twin-to-twin transfusion syndrome. Am J Obstet Gynecol. 2010;203:479. e1-e6.

65. Delabaere A, Leduc F, Reboul Q, Fuchs F, Wavrant S, Fouron JC, et al. Prediction of neonatal outcome of TTTS by fetal heart and Doppler ultrasound parameters before and after laser treatment. Prenat Diagn. 2016;36:1199-1205.

66. Martínez JM, Bermúdez C, Becerra C, López J, Morales WJ, Quintero RA. The role of Doppler studies in predicting individual intrauterine fetal demise after laser therapy for twin-twin transfusion syndrome. Ultrasound Obstet Gynecol. 2003;22:246-251.

67. Crombleholme TM, Shera D, Lee H, Johnson M, D'Alton M, Porter F, et al. A prospective, randomized, multicenter trial of amnioreduction vs selective fetoscopic laser photocoagulation for the treatment of severe twin-twin transfusion syndrome. Am J Obstet Gynecol. 2007;197:396.e1-e9. 